Investigations

\title{
Comparison Analysis of Species Composition of Entomopathogenic Fungi Isolated from Bark Beetles (Coleoptera: Scolytidae)
}

\author{
${ }^{1}$ Rauza Abdukerim, ${ }^{2}$ Georgy Lednev, ${ }^{3}$ Miloš Trýzna, ${ }^{3}$ Pavel Ryšánek and ${ }^{3}$ Miroslav Zouhar \\ ${ }^{1}$ Kazakh National Agrarian University 050012, 8, st.Abay Avenue, Almaty, The Republic of Kazakhstan \\ ${ }^{2}$ Russian Federal Research Institute of Plant Protection, Pushkin, St. Petersburg, 196608 Russia \\ ${ }^{3}$ Czech University of Life Sciences, 165 21, Kamýcká 129, Praha 6-Suchdol, Czech Republic
}

Article history

Received: 14-07-2017

Revised: 02-12-2017

Accepted: 18-01-2018

Corresponding Author: Rauza Abdukerim,

Kazakh National Agrarian

University 050012, 8, st.Abay

Avenue, Almaty, The Republic

of Kazakhstan

Email: rauza91@mail.ru

\begin{abstract}
The monitoring outbreaks of bark beetles, flight activity of imago and development of larvae were conducted with pheromone traps and trap logs. We found more than 50 dead adults with symptoms white muscardine from several points under the bark. Healthy adults of Ips typographus without any pathogenic symptoms collected from pheromone traps and trap logs under bark in the forest Czech Bohemian Switzerland (České Švýcarsko). For adaptation bark beetles Ips typographus in the laboratory conditions and excluded any other abiotic factors as a potential reason for their mortality. They were placed in bark in the Petri plates with filter paper and treated by $1 \mathrm{ml}$ of entomopathogenic fungi conidial suspensions. The isolates Bcz38 and Inc2 showed low level of mortality of Ips typographus. But the isolate Bcz2, Bcz8, Bcz9, Bcz12-Bcz25 of B.bassiana and Bcz31 B.pseudobassiana had high virulence against of Ips typographus $100 \%$.
\end{abstract}

Keywords: Entomopathogenic Fungi, Beauveria bassiana, Ips typographus

\section{Introduction}

One of the most dangerous groups of pest xylophages in coniferous forests is bark beetles (Coleoptera, Curculionidae, Scolytinae). Bark beetles have been often serious pests in spruce monocultures but also in close-tonature forests in the last decades (Juha and Turčáni, 2008; Holuša et al., 2012). Ips typographus found throughout the natural range of its main host Picea abies. The spruce bark beetle, Ips typographus (L.) (Coleoptera: Curculionidae, Scolytinae), is one of the most destructive insects infesting spruce forests in Europe (Faccoli and Bernardinelli, 2014).

The outbreaks of Ips typographus (L.) in Central Europe after severe storms in the 1990s triggered extensive research (Wermelinger, 2004).

The aim of forest managing against bark beetles is to minimize attacks on living trees. The measures most commonly applied for this purpose are clearing windthrows (trees uprooted or broken by wind), sanitation felling of infested trees and the installation of trapping devices. The felling and removal of infested trees from forests are one of the most effective control methods (Wegensteiner and Weiser, 1996). There is a long-termdiscussion about possibility of sanitary cutting of trees infested by bark beetles particularly in strictly protected areas. Strictly protected zones of natural parks become often the areas with large-scale bark beetles outbreaks. On the places where removing of cut trees is difficult, $\operatorname{logs}$ are left on site. No chemical treatment is used within the national park (Knïlek and Trýzna, 2014).

Synthetic formulations of entomopathogenic microorganisms, such as fungi, bacteria, and viruses, may also be useful for managing bark beetle populations. Efforts have focused largely on the fungus Beauveriabassiana (bals.) Vuill. (Ascomycota: Hypocreales), which has been demonstrated to cause high levels of mortality in several species of bark beetles, including I. typographus (Prishepa and Kanapackaya, 2005; Wegensteiner, 2000).

\section{Materials and Methods}

The monitoring of flight activity and development Ips typographus was studied in the several points of Czech Bohemian Switzerland (České Švýcarsko) with pheromone traps and logs, at an altitude of 340-471 $\mathrm{m}$ above sea level (N $\quad 50.927371^{\circ} \mathrm{W} \quad 14.447837^{\circ}$; N $\quad 50.813300^{\circ} \mathrm{W}$ $14.388281^{\circ}$; N $50.866989^{\circ} \mathrm{W} 14.319150^{\circ}$ ) in 2016 (Fig. 1). 


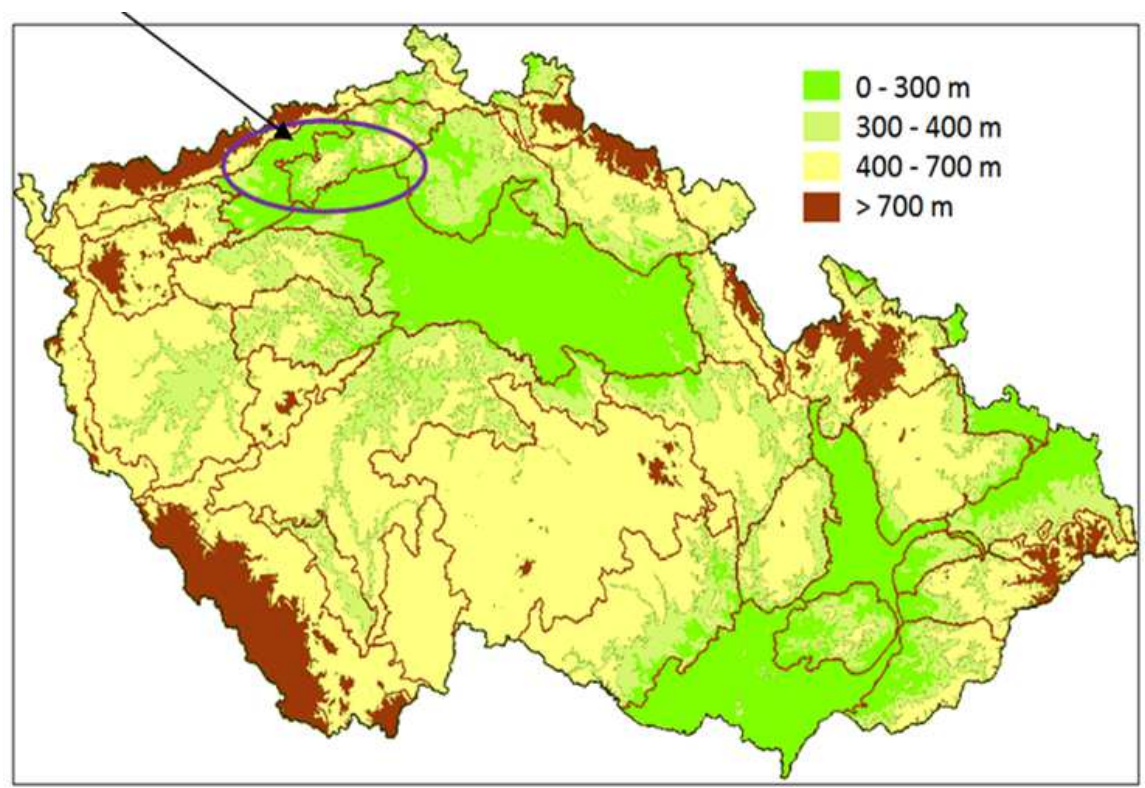

Fig. 1: Map of Czech Republic with marked research location

Traps were controlling weekly from April through September. The number of bark beetles caught was determined or by direct counting or measured by volume. Naturally infected adults bark beetles were collected under the bark. We found more than 70 adults with symptoms mycosis white muscardine. From this dead bark beetles were isolated fresh 49 isolates entomopathogenic fungi on the medium Potato Dextrose Agar (PDA) and Sabouraud Dextrose Agar (SDA). PDA and SDA were prepared and sterilized by autoclave, after that added antibiotic to avoid bacterial contamination.

In the process of isolating a pure culture of new isolates entomopathogenic fungi, they was identified respectively to morphological characteristics when growing on the medium PDA and SDA: Size, shape, structure, edge of colonies (Lednev et al., 2002). They are growing very well on nutrient medium PDA and SDA. On SDA main mass of culture has morphology characteristic of Beauveria sp.: Rounded colonies of white or beige color, often with darker color in the center, dense, mealy, mealy-fluffy or powdery.

Bio assays to evaluate the efficacy of entomopathogenic fungi isolates against adults of I.typographus were conducted under laboratory conditions in the Czech University Of Life Science. Healthy insects were placed in Petri plates with filter paper disks in the optimal conditions. They were treated by $1 \mathrm{ml}$ of entomopathogenic fungi conidial suspensions in concentration $1 \times 10^{7}$.

\section{Molecular Identification of Strains}

After cultivation, DNA from the isolates on PDA media for 14 days at $25 \pm 1^{\circ} \mathrm{C}$, was extracted by the GenElutePlant Genomic DNA Miniprep Kita.
Determine the concentration and purity of the DNA by $1.5 \%$ agarose gel electrophoresis.

The fragment of DNA of EF1- $\alpha$ was also amplified by using primers EF1T ATGGGTAAGGARGACAAGAC-3') and 1567R (5'ACHGTRCCRATACCACCSATCTT-3'). PCR conditions consisted of $5 \mathrm{~min}$ at $95^{\circ} \mathrm{C}$ followed by 35 cycles of $1 \mathrm{~min}$ at $94^{\circ} \mathrm{C}, 45 \mathrm{~s}$ at $54^{\circ} \mathrm{C}$ and $1 \mathrm{~min}$ at $72^{\circ} \mathrm{C}$ with a final extension of $4 \mathrm{~min}$ at $72^{\circ} \mathrm{C}$ (Atkins et al., 2005).

\section{Data Analysis}

Results of DNA sequences were collected and edited with software Mega7. Alignment of sequences ClustaW.For phylogenetic analysis was use programs jModelTest, Paup*v4., MrBayes 3.1.2., TreeView.

Mortality values were corrected according to Abbott's formula (Abbott, 1925). For statistical evaluation of all experiments use one-way ANOVA and Fisher LSD in IBM statistic program. For all studies, controls were always statistically different from treatments $(\mathrm{p}<0.05)$.

\section{Results}

The field study was conducted in the Czech Bohemian Switzerland (České Švýcarsko) between April and September 2016. The flight activity, outbreaks of bark beetles and development were controlling Ips typographus with pheromone traps and trap logs. We found more than 50 dead adults with symptoms mycosis white muscardine from several points under the bark. The fungus was isolated and cultivated on PDA medium to determine some of the morphological features (Fig. 2). The colony color of entomopathogenic fungi was white on PDA medium. 


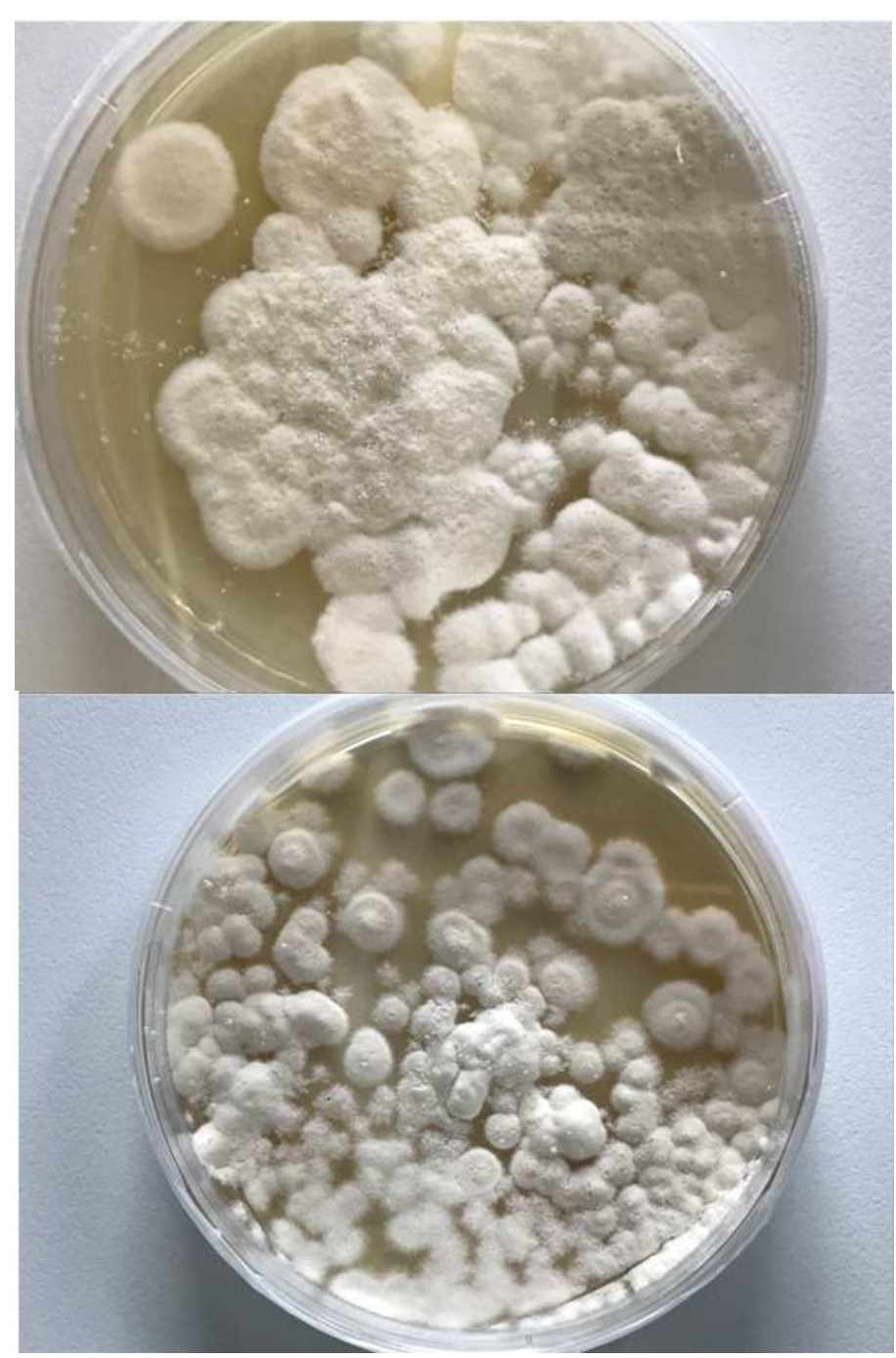

Fig. 2: Entomopathogenic fungi were isolated from bark beetles

Table 1: Characterization of haplotypes EF1- $\alpha$ isolates from bark beetles were found Czech bohemian in comparison with the records in genbank

\begin{tabular}{|c|c|c|c|c|c|}
\hline Strains & Haplotypes & Strain in Genbank & $\begin{array}{l}\text { Access number } \\
\text { in Genbank }\end{array}$ & Isolates & $\begin{array}{l}\text { Level of similarity } \\
\text { with a typical strain } \\
\text { from Genbank, } \%\end{array}$ \\
\hline B. bassiana & $\mathrm{A}(09 / 16)$ & EABb 09/16 & KX911197.1 & $\begin{array}{l}\text { Bcz1-Bcz30, Bcz32- } \\
\text { Bcz34, Bcz36-Bcz47 }\end{array}$ & 100 \\
\hline B (492) & L492BA & JQ043236.1 & Bcz35 & 100 & \\
\hline Beauveriacaledonica & A (4302) & ARSEF 4302 & HQ881014.1 & Inc2 & 100 \\
\hline B. pseudobassiana & $\mathrm{A}(09 / 05)$ & $\mathrm{EABb} 09 / 05$ & KJ536059.1 & Bcz31 & 100 \\
\hline I. farinosa & A (1031) & YHIFXGL-I1031 & KP743154.1 & Isc 1 ,Isc 2 & 100 \\
\hline
\end{tabular}

They was identified as Beauveria sensu lato based on morphological specificity. Additionally, we sequenced partial sequence of EF1- $\alpha$ to confirm 45 isolates $B$. bassiana, 1 isolates Beauveria caledonica, 1 isolates $B$. pseudobassiana and two isolates I. farinose (Table 1). Results showed in all new isolates from bark beetles dominated entomopathogenic fungi B. bassiana $92 \%$, respectively Beauveria caledonica $2 \%$ and $B$. pseudobassiana $2 \%$, I. farinosa $4 \%$ (Fig. 3).

Healthy adults of Ips typographus without any pathogenic symptoms collected from pheromone traps and trap logs under bark in the forest Czech Bohemian Switzerland (České Švýcarsko). For adaptation bark beetles Ips typographus in the laboratory conditions and 
excluded any other abiotic factors as a potential reason for their mortality. They were placed in bark in the Petri plates with filter paper and treated by $1 \mathrm{ml}$ of entomopathogenic fungi conidial suspensions. The isolates Bcz38 and Inc2 showed low level of mortality of Ips typographus. But the isolate Bcz2, Bcz8, Bcz9, Bcz12-Bcz25 of B.bassiana and Bcz31

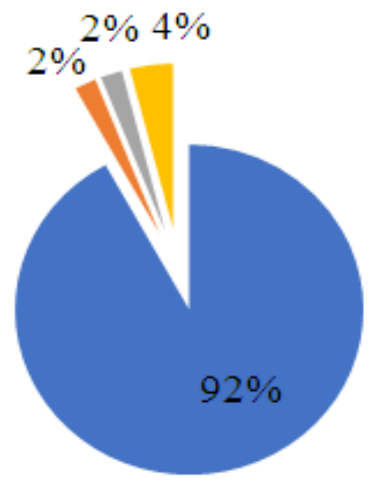

B.pseudobassiana had high virulence against of Ips typographus $100 \%$ (Table 2).

After 5 days inoculation, entomopathogenic fungi killed bark beetles. Dead beetles transfer in the humidity Petri dishes to determine the reason of mortality abiotic factors or influence of entomopathogenic fungi (Fig. 4).

Fig. 3: Structure of species composition of entomopathogenic anamorphic ascomycetes isolated from adults dead bark beetles

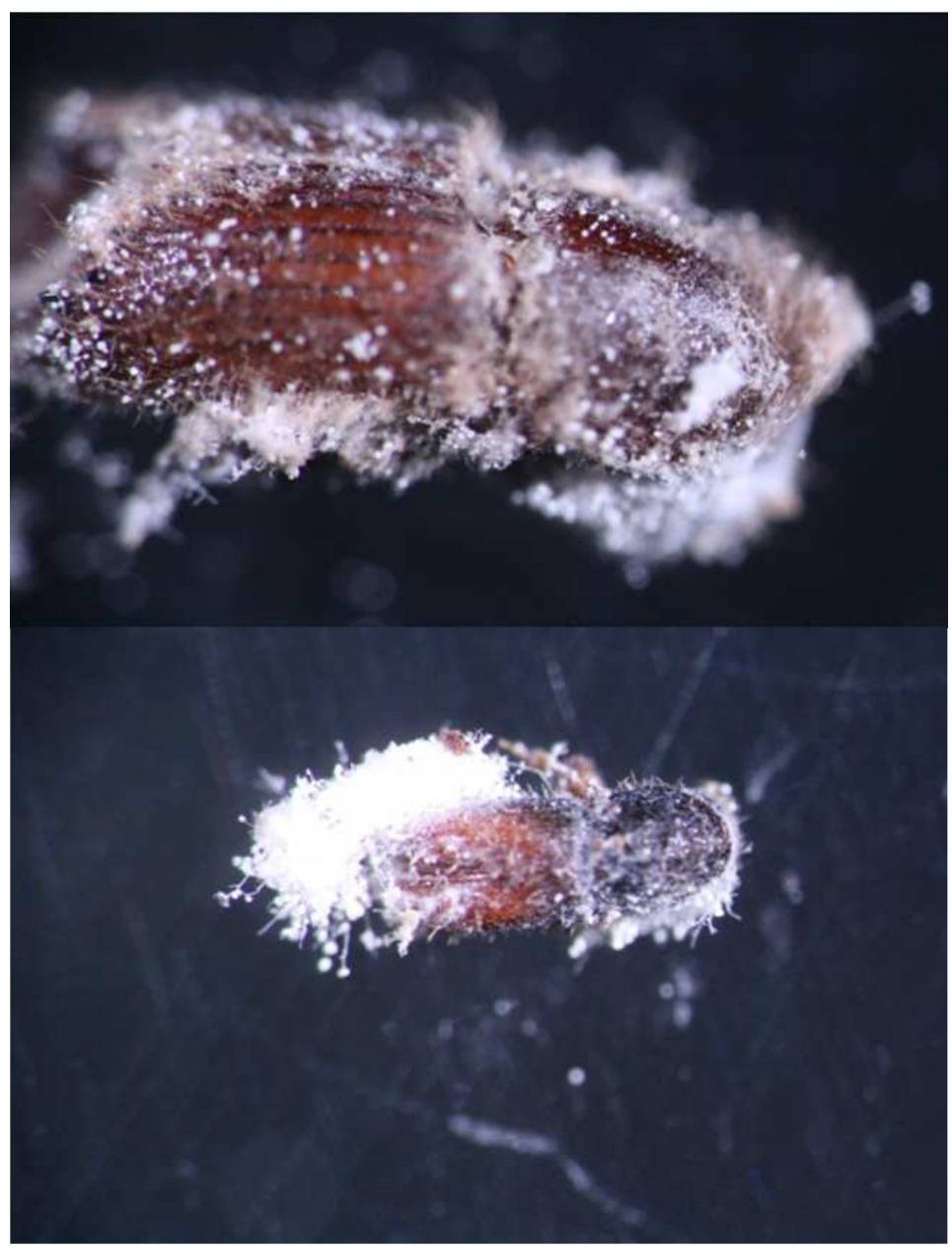

Fig. 4: Mycosis on adult bark beetles caused by isolate of B. bassiana 
Dinara Asylbekovna Begaliyeva et al. / OnLine Journal of Biological Sciences 2018, 18 (1): 62.68 DOI: 10.3844/ojbsci.2018.62.68

Table 2: Efficacy of entomopathogenic fungi strains in bioassays with adults Ips typographus $\%$ Bark beetles mortality, days

\begin{tabular}{|c|c|c|c|c|c|}
\hline Isolates & 5 & 7 & 9 & 11 & $\begin{array}{l}\text { Beetles with } \\
\text { signs of mycosis }\end{array}$ \\
\hline $\mathrm{BCz} 1$ & $47.5 \pm 11.0$ & $70 \pm 4.0$ & $90 \pm 7.0$ & 100 & 68 \\
\hline $\mathrm{BCz} 2$ & $35 \pm 8.6$ & $50 \pm 4.0$ & 100 & 100 & 89 \\
\hline $\mathrm{BCz} 3$ & $45 \pm 8.6$ & $55 \pm 5$ & $80 \pm 4.0$ & 100 & 93 \\
\hline $\mathrm{BCz} 4$ & $27.5 \pm 6.2$ & $50 \pm 4.0$ & $85 \pm 2.8$ & 100 & 74 \\
\hline $\mathrm{BCz} 5$ & $45.5 \pm 2.8$ & $60 \pm 4.0$ & $80 \pm 7.0$ & 100 & 59 \\
\hline $\mathrm{BCz} 6$ & $22.5 \pm 4.7$ & $50 \pm 4.0$ & $75 \pm 2.8$ & 100 & 67 \\
\hline $\mathrm{BCz} 7$ & $67.5 \pm 10.3$ & $75 \pm 10.4$ & $92.5 \pm 4.7$ & 100 & 50 \\
\hline $\mathrm{BCz} 8$ & $22.5 \pm 4.7$ & $50 \pm 4.0$ & 100 & 100 & 80 \\
\hline BCz9 & $22.5 \pm 4.7$ & $50 \pm 5.7$ & 100 & 100 & 89 \\
\hline BCz10 & $15 \pm 6.4$ & $85 \pm 3.7$ & $92.5 \pm 4.7$ & 100 & 54 \\
\hline BCz11 & $40 \pm 12.2$ & $55 \pm 14.4$ & $85 \pm 2.8$ & 100 & 90 \\
\hline $\mathrm{BCz} 12$ & $20.0 \pm 4.4$ & $50 \pm 3.1$ & 100 & 100 & 66 \\
\hline $\mathrm{BCz} 13$ & $60 \pm 19.5$ & $80 \pm 10.8$ & 100 & 100 & 70 \\
\hline BCz15 & $50 \pm 7.0$ & $82.5 \pm 4.7$ & 100 & 100 & 64 \\
\hline BCz16 & $60 \pm 10.8$ & $72.5 \pm 5.7$ & 100 & 100 & 76 \\
\hline $\mathrm{BCz} 17$ & $50 \pm 12.5$ & $80 \pm 16.8$ & 100 & 100 & 89 \\
\hline $\mathrm{BCz} 18$ & $75 \pm 18.9$ & $77.5 \pm 14.3$ & 100 & 100 & 90 \\
\hline BCz19 & $40 \pm 12.9$ & $57.5 \pm 12.5$ & 100 & 100 & 71 \\
\hline $\mathrm{BCz} 20$ & $40 \pm 13.5$ & $77.5 \pm 13.1$ & 100 & 100 & 68 \\
\hline $\mathrm{BCz} 21$ & $57.5 \pm 16.5$ & $62.5 \pm 13.1$ & 100 & 100 & 67 \\
\hline $\mathrm{BCz} 22$ & $72.5 \pm 2.5$ & $80 \pm 12.2$ & 100 & 100 & 78 \\
\hline $\mathrm{BCz} 23$ & $65 \pm 6.4$ & $72.5 \pm 8.5$ & 100 & 100 & 77 \\
\hline $\mathrm{BCz} 24$ & $70 \pm 10.8$ & $90 \pm 5.7$ & $90 \pm 5.7$ & 100 & 65 \\
\hline $\mathrm{BCz} 25$ & $32.5 \pm 8.5$ & $42.5 \pm 12.5$ & 100 & 100 & 100 \\
\hline BCz26 & $42.5 \pm 8.5$ & $62.5 \pm 15$ & $90 \pm 10.0$ & 100 & 56 \\
\hline $\mathrm{BCz} 27$ & $42.5 \pm 8.5$ & $57.5 \pm 15.0$ & $90 \pm 5.7$ & 100 & 92 \\
\hline $\mathrm{BCz} 28$ & $30 \pm 4.0$ & $55 \pm 12.9$ & 100 & 100 & 72 \\
\hline BCz29 & $50 \pm 10.8$ & $67.5 \pm 10.3$ & 100 & 100 & 67 \\
\hline $\mathrm{BCz} 30$ & $45 \pm 17.5$ & $72.5 \pm 8.5$ & 100 & 100 & 90 \\
\hline BCz31 & $35 \pm 8.6$ & $72.5 \pm 22.1$ & 100 & 100 & 100 \\
\hline BCz32 & $50 \pm 4.0$ & $62.5 \pm 14.3$ & 100 & 100 & 82 \\
\hline BCz33 & $45 \pm 17.5$ & $57.5 \pm 8.5$ & 100 & 100 & 70 \\
\hline BCz34 & $22.5 \pm 4.7$ & $42.5 \pm 8.5$ & $75 \pm 2.8$ & 100 & 93 \\
\hline BCz35 & $35 \pm 8.6$ & $57.5 \pm 8.5$ & 100 & 100 & 70 \\
\hline BCz36 & $37.5 \pm 13.1$ & $50 \pm 8.1$ & $75 \pm 2.8$ & 100 & 93 \\
\hline BCz37 & $25 \pm 2.8$ & $55 \pm 5.0$ & $72.5 \pm 2.5$ & 100 & 60 \\
\hline BCz38 & $42.5 \pm 16.5$ & $50 \pm 20.8$ & $67.5 \pm 10.3$ & 100 & 100 \\
\hline BCz39 & $24 \pm 4.0$ & $45 \pm 8.5$ & 100 & 100 & 65 \\
\hline $\mathrm{BCz} 40$ & $65 \pm 5.0$ & $72.5 \pm 2.5$ & $80 \pm 7.0$ & 100 & 91 \\
\hline $\mathrm{BCz} 41$ & $50 \pm 20.0$ & $60 \pm 19.5$ & $75 \pm 25.1$ & 100 & 57 \\
\hline $\mathrm{BCz} 42$ & $57.5 \pm 14.3$ & $75 \pm 18.9$ & $87.5 \pm 7.5$ & 100 & 70 \\
\hline $\mathrm{BCz} 43$ & $62 \pm 8.5$ & $75 \pm 14.7$ & $74 \pm 2.4$ & 100 & 94 \\
\hline $\mathrm{BCz} 44$ & $55 \pm 17.0$ & $65 \pm 6.5$ & $75 \pm 12.5$ & $80 \pm 11.5$ & 63 \\
\hline $\mathrm{BCz} 45$ & $45 \pm 2.8$ & $50 \pm 4.0$ & $80 \pm 8.1$ & 100 & 88 \\
\hline $\mathrm{BCz} 46$ & $65 \pm 12.5$ & $75 \pm 10.4$ & $85 \pm 12.9$ & 100 & 63 \\
\hline $\mathrm{BCz} 47$ & $50 \pm 12.9$ & $60 \pm 4.0$ & $70 \pm 11.2$ & 100 & 69 \\
\hline IsCz1 & $30 \pm 10.0$ & $58 \pm 1.3$ & $75 \pm 15.0$ & 100 & 78 \\
\hline $\mathrm{IsCz} 2$ & $30 \pm 12.9$ & $50 \pm 10.0$ & $70 \pm 20.8$ & $85 \pm 2.8$ & 51 \\
\hline Inc2 & $40 \pm 14.1$ & $50 \pm 3.2$ & $60 \pm 8.3$ & $65 \pm 12.5$ & 61 \\
\hline Control & 0.00 & 0.00 & 0.00 & $10 \pm 2.3$ & \\
\hline $\mathrm{LSD}_{.05}$ & 11.3 & 10.7 & 5.4 & 2.3 & \\
\hline
\end{tabular}




\section{Discussion}

In the study 49 new isolates from bark beetles were observed. In the process of isolating a pure culture of new isolates entomopathogenic fungi, they was identified respectively to morphological characteristics when growing on the medium PDA and SDA: Size, shape, structure, edge of colonies (Lednev et al., 2002). They are growing very well on nutrient medium PDA and SDA. On SDA main mass of culture has morphology characteristic of Beauveria sp.: Rounded colonies of white or beige color, often with darker color in the center, dense, mealy, mealy-fluffy or powdery. Additionally, we sequenced partial sequence of EF1- $\alpha$ to confirm 45 isolates $B$. bassiana, 1 isolates Beauveriacaledonica, 1 isolates $B$. pseudobassiana and two isolates I. Farinose. Results showed in all new isolates from bark beetles dominated entomopathogenic fungi $B$. bassiana 92\%, respectively Beauveriacaledonica $2 \%$ and B. pseudobassiana $2 \%$, I. farinosa 4\%. A similar group of entomopathogenic anamorphic ascomycetes on bark beetles is also characteristic for some European countries (Takov et al., 2007). After analysis of the location largest number of samples at an altitude of $340 \mathrm{~m}$ above sea level (more than $90 \%$ ) was collected among only B. bassiana. An assessment of the intraspecies of the identified taxa has been shown that both species of the genus Beauveria represent two haplotypes, and the rest-one by one.

After 11th days, efficacy adjusted for control (according to Abbott's formula) varied from 60 to $100 \%$. The strains Bcz2, Bcz8, Bcz9, Bcz12- Bcz25 and Bcz31showed high virulence effect to adults of Ips typographus $100 \%$ after 9 days. In our study, we focused to find isolates from bark beetles and definitions of virulence against this pest.

The virulence of $B$. bassiana, I. farinosa, $M$. anisopliae and $V$. lecaniiwas tested on I. typographus with significant mortality effect, indicating their suitability for biological control against this forest pest (Popa et al., 2012).

\section{Conclusion}

In the study, the purpose was testing the effect of entomopathogenic fungal spores on mortality and infectivity of spruce bark beetle. Study of the influence of selected isolates demonstrated positive results for the use of biological protection. In the result of the data is convincing about this, entomopathogenic fungi isolates from the Czech Republic could use to produce mycoinsecticides against bark beetles.

\section{Acknowledgements}

This research was supported by the project Casia III is an Erasmus Mundus Partnership with Kazakh National Agrarian University and Czech University of Life Sciences.

\section{Author's Contributions}

Participated in all experiments, coordinated the dataanalysis and contributed to the writing of the manuscript.

\section{Ethics}

Authors declared no conflicts of interests.

\section{References}

Abbott, W.S., 1925. A method of computing the effectiveness of an insecticide. J. Econ. Entomol., 18: 265-267.

Atkins, S.D., I.M. Clark, S. Pande, P.R. Hirsch and B.R. Kerry, 2005. The use of real-time PCR and species-specific primers for the identification and monitoring of Paecilomyceslilacinus. FEMS Microbiol. Ecol., 51: 257-264.

Faccoli, M. and I. Bernardinelli, 2014. Composition and elevation of spruce forests affect susceptibility to bark beetle attacks: Implications for forest management. Forests, 5: 88-102. DOI: 10.3390/f5010088

Holuša, J., K. Lukášová and J. Lubojacký, 2012. Comparison of seasonal flight activity of Ips typographus and Ips duplicatus. Sci. Agric. Bohemica, 43: 109-115.

Juha, M. and M. Turčáni, 2008. Správa národního parku a chráněné krajinné oblasti šumava ve vimperku; fld zu praha - netradiní zpsoby boje s lýkožroutem smrkovým - ips typographus 1. (coleoptera: scolytidae)- zprávy lesnického výzkumu, svazek 53.

Kní̈ek, M. and M. Trýzna, 2014. Bark beetles on white pine in Bohemian Switzerland National Park. Forestry and Game Management Research Institute. Czech Republic.

Lednev, G.R., B.A. Borisov and G.V. Mitina, 2002. Pathogens of insect mycoses (diagnosis manual). Russian Academy of Agricultural Sciences, AllRussian Scientific Research Institute for Plant Protection, St. Petersburg, Russia.

Popa, V., E. Deziel, R. Lavallee, E. Bauce and C. Guertin, 2012. The complex symbiotic relationships of bark beetles with microorganisms: A potential practical approach for biological control in forestry. Pest Manage. Sci., 68: 963-975.

Prishepa, L.I. and V.A. Kanapackaya, 2005. Prospects for using the Beverin-BL biopreparation in limiting the number of bark beet-typographer (Ips typographus L). Proceedings of the Sustainable Forest Development and Rational Use of Forest Resources: Materials of the International Scientific and Practical Conference, (SPC'05), Minsk, pp: 211-213.

Takov, D., D. Doychev, R. Wegensteiner and D. Pilarska, 2007. Study of Bark Beetles (Coleoptera, Scolytidae) Pathogens from Coniferous stands in Bulgaria. Acta Zool. Bulgarica, 59: 87-96. 
Wegensteiner, R. and J. Weiser, 1996. Untersuchungen zum Auftreten von Pathogenen bei Ips typographus L. (Coleoptera, Scolytidae) aus einem Naturschutzgebiet im Schwarzwald (Baden-Württemberg). Anzeiger für Schädlingskunde, Pflanzenschutz, Umweltschutz, 69: 162-167. DOI: 10.1007/BF01906808

Wegensteiner, R., 2000. Laboratory evaluation of Beauveria bassiana (Bals.) Vuill. and Beauveria brongniartii (Sacc.) Petch against the four eyed spruce bark beetle, Polygraphus poligraphus (L.)(Coleoptera, Scolytidae). Proceedings of the 7th European Meeting of the IOBC/WPRS Working Group: Insect Pathogens and Insect Parasitic Nematode Entitled 'Capturing the Potential of Biological Control', Mar. 22-26, Vienna, Austria, Bulletin OILB/SROP, pp: 161-166.
Wermelinger, B., 2004. Ecology and management of the spruce bark beetle Ips typographus - a review of recent research. Forest Ecol. Manage., 202: 67-82. 